Article

\title{
Fabrication of Poly(amide-co-ester) Solvent Resistant Nanofiltration Membrane from P-nitrophenol and Trimethyl Chloride via Interfacial Polymerization
}

\author{
Ayang Zhou *, Lin Li, Mengying Li and Qi Chen \\ School of Materials and Chemical Engineering, Chuzhou University, Chuzhou 239000, China; \\ lilin129@foxmail.com (L.L.); lmy00002022@163.com (M.L.); 17682106362@163.com (Q.C.) \\ * Correspondence: zhouyayang888@chzu.edu.cn; Tel.: +86-0551-3511052
}

check for

updates

Citation: Zhou, A.; Li, L.; Li, M.;

Chen, Q. Fabrication of

Poly(amide-co-ester) Solvent

Resistant Nanofiltration Membrane

from P-nitrophenol and Trimethyl

Chloride via Interfacial

Polymerization. Separations 2022, 9,

28. https://doi.org/10.3390/

separations 9020028

Academic Editor: Alessandra

Criscuoli

Received: 28 December 2021

Accepted: 19 January 2022

Published: 21 January 2022

Publisher's Note: MDPI stays neutral with regard to jurisdictional claims in published maps and institutional affiliations.

Copyright: (C) 2022 by the authors. Licensee MDPI, Basel, Switzerland. This article is an open access article distributed under the terms and conditions of the Creative Commons Attribution (CC BY) license (https:// creativecommons.org/licenses/by/ $4.0 /)$.

\begin{abstract}
P-nitrophenol (PNP), a refractory hazardous substance, has not been efficiently utilized so far. In this paper, PNP is used as a membrane modification material for preparing poly(amideco-ester) composite nanofiltration membrane. An organic solvent nanofiltration (OSN) membrane was prepared via interfacial polymerization reactionby using PNP and trimethyl chloride (TMC) on a ethylenediamine (EDA) crosslinked polyetherimide substrate. The results of ATR-FTIR and XPS show that interfacial polymerization occurs among with PNP and TMC and the terminal amine groups on the ethylenediamine crosslinked -PEI support forming a poly(amide-co-ester) toplayer. The NF-1PNP membrane maintained stable DMF performance permeance of $2.2 \mathrm{~L} \mathrm{~m}^{-2} \mathrm{~h}^{-1} \mathrm{bar}^{-1}$ and rejection of $98 \%$ for Rose Bengal red (RB $1017.64 \mathrm{~g} \mathrm{~mol}^{-1}$ ) in $36 \mathrm{~h}$ continuous separation process. Furthermore, the average pore diameter of the two membranes including NF-1PNP and NF-1.25PNP, which is 0.40 and $0.36 \mathrm{~nm}$, respectively. This study not only provides a good way for the preparation of OSN membrane, but also provides a good demonstration for the comprehensive utilization of PNP and other toxic and harmful pollutants.
\end{abstract}

Keywords: P-nitrophenol; interfacial polymerization; poly(amide-co-ester); membrane; nanofiltration; solvent resistant

\section{Introduction}

Membrane technology is a new high-efficiency separation technology. Compared with traditional separation processes such as distillation and extraction, it has the characteristics of being energy saving and environmentfriendly. It is widely used in medicine, food, and petrochemical industries [1-3]. Membrane material is the key of membrane separation technology, and membrane equipment is the carrier of it. The coupling engineering technology between membrane separation technology and other chemical unit operation is the direction of membrane separation technology promotion [3-5]. At present, membrane materials are widely used in water treatment, such as seawater desalination and dye decolorization. In recent years, with the needs of separating organic systems, organic solvent resistant composite membranes have been more and more used. Organic solvent nanofiltration (OSN) technology, generally performed at room temperature, retains larger solutes and allows organic solvents and solutes with smaller molecular weights to pass through the membrane. OSN technology plays a key role in the separation of organic phases, such as catalyst regeneration, antibiotic separation, and so on [6,7].

Integrally skinned symmetric membrane and thin film composite (TFC) membrane are the two most prepared solvent resistant membranes. The preparation process of ISA membrane includes first preparing the support layer by phase transfer method, and then crosslinking the support layer. The selected crosslinking agents are usually organic amines such as ethylenediamine, as well as other crosslinking agents such as glutaraldehyde 
or silane coupling agent. However, some ISA membranes showed poor physical properties and are prone to compaction and aging inextremely harsh environments [8-11]. TFC membrane consists of supporting layer and top layer. The support layer is usually made of polyamide or polydimethylsiloxane. In order to ensure the stability of the support layer, some preparation processes also need to crosslink the supporting layer. The top layer plays a decisive role in the performance of TFC membrane. It is usually prepared by interfacial polymerization, layer by layer self-assembly, incorporating nanomaterial such as MOFs, $\mathrm{ZIFs}$, and $\mathrm{TiO}_{2}$ nanoparticles into the selective layer and vacuum deposition [12-17]. Interfacial polymerization is still the main method to prepare TFC solvent-resistant composite membrane. For instance, a polyamantadinamide OSN membrane was prepared by introducing an adamantane (AD) structure into the active layer via 3-amino-1-adamantanol (AAMO) interfacial polymerization with acyl chloride, which had a permeance of $29.5 \mathrm{~L} \mathrm{~m}^{-2} \mathrm{~h}^{-1} \mathrm{Mpa}^{-1}$ and a rejection about $84.4 \%$ for Fast Green FCF $\left(808.85 \mathrm{~g} \mathrm{~mol}^{-1}\right)$ in methanol $[18,19]$. Common monomers are amines and acyl chlorides, which form a linked polyamide (PA) network. The polyamide selective layer is prepared by two reaction monomers (TMC) and m-phenylenediamine (MPD) via interfacial polymerization method [20], which has good solvent resistance in alcohols [21]. So far, the preparation of thin film composite (TFC) OSN membrane with high permeability and selectivity is still a great challenge. More and more reports on OSN membrane mainly focus on the optimization of IP reaction process and the selection of various monomers. A variety of monomers, from simple amines to macromolecules with inherent structure, and then to naturally occurring molecules have been explored. The formed networks now include polyester, polyarylate, and poly(ether imide). For instance, a poly(ether imide) OSN membrane was prepared by the interfacial polymerization of 1,2,4,5-benzene tetracarbonyl chloride and the mixed amines of ethylenediamine (EDA) and poly(ethy-leneimine), which had a permeance of $5.15 \mathrm{~L} \mathrm{~m}^{-2} \mathrm{~h}^{-1} \mathrm{bar}^{-1}$ and a rejection about $74.4 \%$ for Rose Bengal (RB, $808.85 \mathrm{~g} \mathrm{~mol}^{-1}$ ) in methanol [22]. A polyarylester OSN membrane was synthesized by vanillic alcohol and TMC, which exhibited DMSO permeance about $21 \mathrm{~L} \mathrm{~m}^{-2} \mathrm{~h}^{-1}$ bar $^{-1}$, as well as a Brilliant Blue R-250 (BB, $825.97 \mathrm{~g} \mathrm{~mol}^{-1}$ ) rejection of $89 \%$ [23]. A polyarylate membrane was constructed from one kind of porous organic cage, namely Noria with terephthaloyl chloride (TPC), which exhibits a permeance for methanol up to $18 \mathrm{~L} \mathrm{~m}^{-2} \mathrm{~h}^{-1} \mathrm{bar}^{-1}$ and a rejection about $97 \%$ for RB [24].

In previous research, we found that lignin compounds have strong solvent resistance and we have been exploring some polyphenols similar to lignin structural units as raw materials of solvent-resistant composite membrane. [25,26]. To further prepare a solvent resistant nanofiltration membrane with excellent performance, we chose another monomer, P-nitrophenol (PNP), which is expected to be used to develop a TFC OSN membrane with an active hydroxyl group. P-nitrophenol is also a refractory hazardous substance with enrichment effect contained in wastewater, which is harmful to aquatic organisms and human health. In recent years, the efficient use of sustainable resources materials and pollutants is gradually being carried out. For instance, TFC membranes were designed and fabricated via interfacial polymerization of shrimp farming waste chitosan and 2,5-furandicarboxaldehyde. The TFC membranes showed excellent acetone permeance up to $12 \mathrm{~L} \mathrm{~m}^{-2} \mathrm{~h}^{-1}$ bar $^{-1}$ with a MWCO value of approximately $317 \mathrm{~g} \mathrm{~mol}^{-1}$ [27] A cellulose/chitosan nanofiltration membrane was prepared using piperazine (PIP) and TMC via interfacial polymerization. The membrane showed a good water flux about $15.64 \mathrm{~L} \mathrm{~m}^{-2} \mathrm{~h}^{-1}$ bar $^{-1}$, and a high rejection rate of $99 \%$ for Methyl Blue [28]. Recently, Park $\mathrm{S}-\mathrm{H}$ et al. reported OSN membranes fabricated solely from sustainable resources such as priamine and tannic acid, green solvents ( $\mathrm{p}$-Cymene, water) and recycled polymer waste (PET), the prepared membrane exhibited a high permeance of $13.7 \mathrm{~L} \mathrm{~m}^{-2} \mathrm{~h}^{-1} \mathrm{bar}^{-1}$ in acetone with a $90 \%$ rejection of styrene dimer $\left(235 \mathrm{~g} \mathrm{~mol}^{-1}\right)$ [29].

In this paper, PNP is used as an interfacial polymerization monomer to react with trimethyl chloride on the excessive ethylenediamine (EDA) crosslinked polyetherimidebased membrane to prepare an OSN membrane. EDA played two important roles, one is to 
suppress the swelling of PEI support and the second role is to anchor the top layer tightly to adhere to the supporting membrane by forming amide bonds with TMC.The results of ATR-FTIR and XPS show that the interfacial polymerization between TMC and PNP took place and the poly(coamido-ester) skin was formed with the terminal amine group on PEI carrier crosslinked by ethylenediamine. PNP reacts with TMC to form ester bond structure and had stable solvent resistance in DMF. Because the yellow solution of PNP has an absorption peak at $425 \mathrm{~nm}$, it is possible to detect and analyze the concentration change trend of PNP interface by ultraviolet in-situ detection, which is helpful to better understand the interface polymerization process.

\section{Materials and Methods}

\subsection{Materials}

P-nitrophenol (PNP) was purchased from Tianjin Heowns Chemical Reagent Co., Ltd. (Tianjin, China). Polypropylene non-woven fabric was supplied by Tianjin Teda Filters Co., Ltd. (Tianjin, China) Polyether imide (Ultem 1000) was supplied by Saudi Basic Industries Corporation (Riyadh, Saudi Arabia). Ethylenediamine (EDA) and dimethylacetamide (DMAc) were supplied by Kemiou Chemical Reagent Co., Ltd. (Tianjin, China). Crystal violet $\left(\mathrm{CV}, 407.98 \mathrm{~g} \mathrm{~mol}^{-1}\right.$ ) wassupplied by Sinopharm Chemical Reagent Co. Ltd. (Shanghai, China). N-dimethylformamide (DMF) was supplied by MYM Biotechnology Co., Ltd. (Shanghai, China). 4-Dimethylaminopyridine (DMAP) was supplied by Macklin (Shanghai, China), which was used as a phase transfer catalyst for interfacial polymerization. All reagents were not purified further.

\subsection{Membrane Preparation}

\subsubsection{Preparation PEI Support and EDA-Crosslinked PEI}

Firstly, PEI was vacuum dried at $120^{\circ} \mathrm{C}$ for $4 \mathrm{~h}$ to remove possible excess moisture and volatile components. Then, $23 \mathrm{wt} \%$ PEI was dissolved in DMAc for $4 \mathrm{~h}$ at $60^{\circ} \mathrm{C}$ with the stirring speed of $600 \mathrm{rpm}$. Then, bubbles in the casting solution are removed by ultrasonic. A steel knife with a gap of $100 \mu \mathrm{m}$ was used to scrape PEI solution onto non-woven fabric and then soak it in deionized water for $1 \mathrm{~h}$. A methanol solution of $6 \%(w / v)$ EDA was added to the PEI surface for $1 \mathrm{~h}$. to prepare a crosslinked membrane as a supporting layer of composite membrane.

\subsubsection{Preparation of PNP Modified TFC Membranes}

Firstly, PNP aqueous solution mixed with $0.3 \%(w / v)$ DMAP was poured into the surface of crosslinked PEI membrane for $2 \mathrm{~min}$ in a constant temperature and humidity box at $25{ }^{\circ} \mathrm{C}$. Then the water on the membrane surface was wiped dry by the absorbent filter paper, $0.1 \%(w / v)$ TMC / hexane solution was poured into crosslinked PEI surface for 1 minute. After that, membrane was put into the microwave oven for $1 \mathrm{~min}$ of thermal strengthening with the frequency of $2450 \mathrm{MHz}$ and output power of $1000 \mathrm{~W}$. After being taken out, the membrane was cleaned with deionized water. The membranes with PNP concentration of $0.5 \%, 0.75 \%, 1.0 \%, 1.25 \%$, and $1.5 \%(w / v)$ were named NF-0.5PNP, NF0.75PNP, NF-1.0PNP, NF-1.25PNP, and NF-1.5PNP respectively. For comparison, membrane $\mathrm{NF}-\mathrm{C}$ is named as the membrane that is directly poured into TMC after being crosslinked by EDA.

\subsection{Membrane Structural Characterization}

ATR-FTIR (Bio Rad FTS, Cambridge, MA, USA) was used to characterize chemical structure of prepared membrane.SEM (LEO, Oberkochen, BW, Germany) was used for characterization of morphology. XPS (Thermo, Waltham, MA, USA) was used to determine the element composition and identify the existence of a specific element of toplayer of membrane. AFM (Seiko, Chiba, Japan) was used to characterize the surface images. All tests were repeated at least three times to obtain the average value and error. Characterization of membrane performance were carried out in a stainless steel dead-end filtration module 
with area of $38.5 \mathrm{~cm}^{2}$. The filtration experiments of polyethylene glycol (PEG), including PEG200, PEG400, PEG600, and PEG800, were carried out to characterize the average pore size distribution of the membrane according to previous reported methods [30,31].

The permeance $\left(P, \mathrm{~L} \mathrm{~m}^{-2} \mathrm{~h}^{-1} \mathrm{bar}^{-1}\right)$ of the membrane is expressed by Equation (1),

$$
P=\frac{V}{A \times t \times \Delta p}
$$

where $V, A, t$, and $\Delta P$ represent the permeated volume, the membrane area, the time interval, and the operating pressure, respectively.

The rejection $(R)$ of the membrane is expressed by Equation (2),

$$
R=\left(1-\frac{C_{p}}{C_{f}}\right) \times 100 \%
$$

where $C p$ and $C f$ represent the concentrations of the permeated solution and the feed solution, respectively. All tests were repeated at least three times to obtain the average value and error.

\subsection{UV Characterization of PNP Consumption Rate}

Before UV characterization, $0.60 \mathrm{~mL}$ PNP solution was added to a cuvette and $0.5 \mathrm{~mL}$ TMC solution was also added into the cuvette. The UV-vis spectrophotometer was used to in situ monitor the absorbance change at $425 \mathrm{~nm}$ of PNP near the organic/aqueous interface.

\section{Results}

\subsection{Morphologies}

Figure 1 displays the morphology of the prepared membranes including NF-C, NF0.75PNP. The surface of NF-C is polymerized by the free terminal amine group produced by the cross-linking process and TMC directly to form polyamide surface. Compared with NF-0.75PNP, NF-C shows a typical peak valley structure of polyamide. Two membranes show unsymmetrical structures composed of finger like pore supporting layer and dense top layer The thickness of the top-layer on top of the macrovoids is about 1570 and $618 \mathrm{~nm}$ for NF-C and NF-0.75PNP, respectively. Compared with NF-0.75PNP, NF-C membrane showed the typical much thicker top layer, which may be due to excessive penetration of TMC into the EDA crosslinked PEI support results in the top layer material intrudes such macrovoids.

As shown in Figure 2, three-dimensional AFM images of three membranes show the ridge and valley structure. The root mean square (RMS) values of surface roughness are $10.02 \pm 0.4 \mathrm{~nm}, 11.2 \pm 0.6 \mathrm{~nm}$, and $42.15 \pm 0.5 \mathrm{~nm}$ for NF-0.75PNP, NF-1PNP, and NF-1.5PNP, respectively. During the process of interfacial polymerization, the migration of aqueous monomer toward the organic solution is faster. This rapid migration can push around and twist the initially formed nascent ultrathin cross-linked skin, thus forming the ridge and valley structure. This indicates that the roughness of the membrane surface increases with the increase of the concentration of p-nitrophenol aqueous monomer during IP process. 


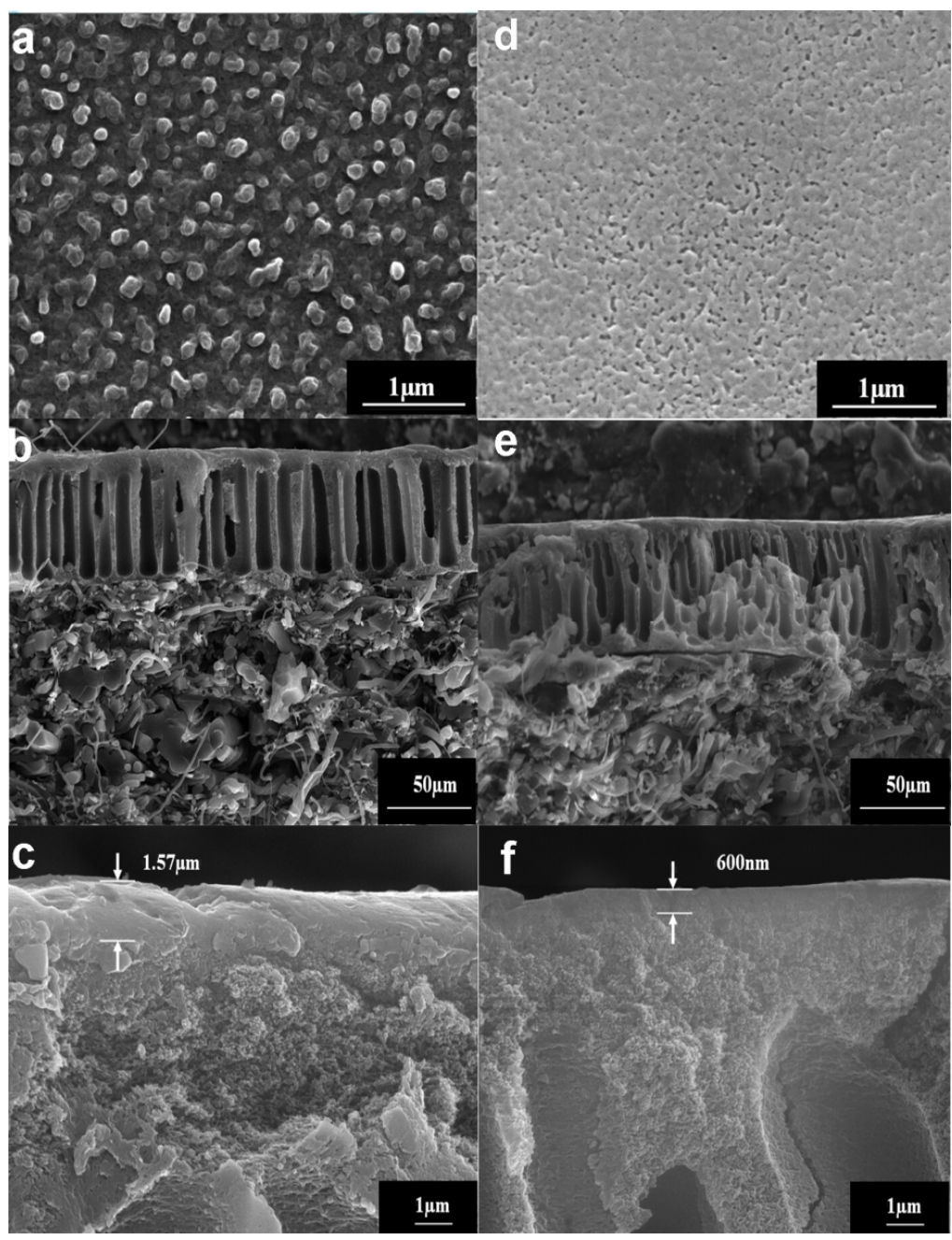

Figure 1. SEM images of NF-C (a-c) and NF-0.75PNP (d-f).

\section{NF-0.75PNP NF-1PNP NF-1.5PNP}
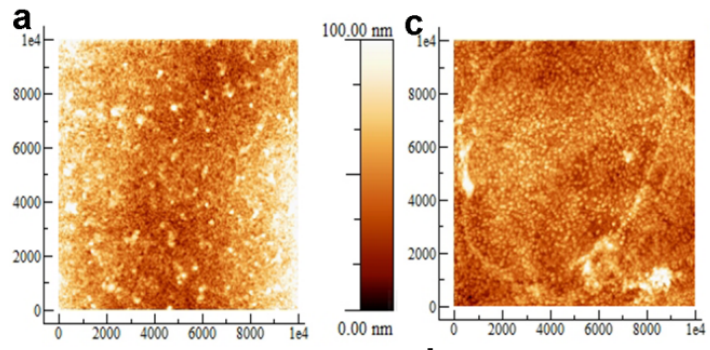

b
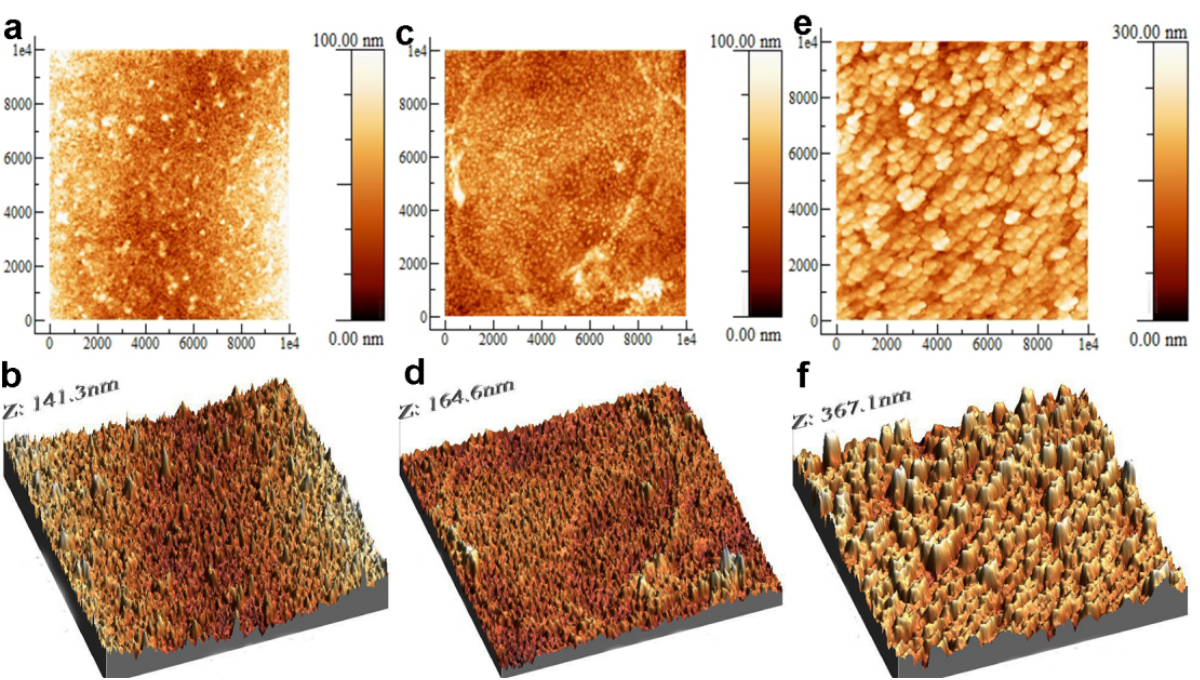

Figure 2. Three-dimensional AFM images of NF-0.75PNP $(\mathbf{a}, \mathbf{b}), \operatorname{NF}-1 P N P(\mathbf{c}, \mathbf{d})$, and NF-1.5PNP $(\mathbf{e}, \mathbf{f})$. 


\subsection{Chemical Structure Analysis}

Figure 3 displays the ATR-FTIR spectra of the NF-C, NF-0.75PNP, NF-1PNP, NF1.25PNP, and NF-1.5PNP membranes. For NF-C, the ATR-FTIR characteristic spectra are located at 1543 and $1643 \mathrm{~cm}^{-1}$ (amide), 1776 (imide) and $3312 \mathrm{~cm}^{-1}$ (amine), respectively, all of which are the structural groups of typical polyamides [32]. The PEI support is crosslinked by excessive EDA, and a large number of free terminal amino groups are distributed on the surface of the membrane. After adding TMC, polyamide was formed on the surface of the membrane. For NF-0.75PNP, NF-1PNP, NF-1.25PNP, and NF-1.5PNP membranes, the spectra contain a series of peaks located at $922(\mathrm{C}-\mathrm{N}$ stretching vibration), 1076 (C-O stretching vibration of amide), and $1720 \mathrm{~cm}^{-1}$, together with $1230 \mathrm{~cm}^{-1}$ (C-O stretching vibration of ester groups), respectively [33], which confirm the polymerization of PNP with TMC.

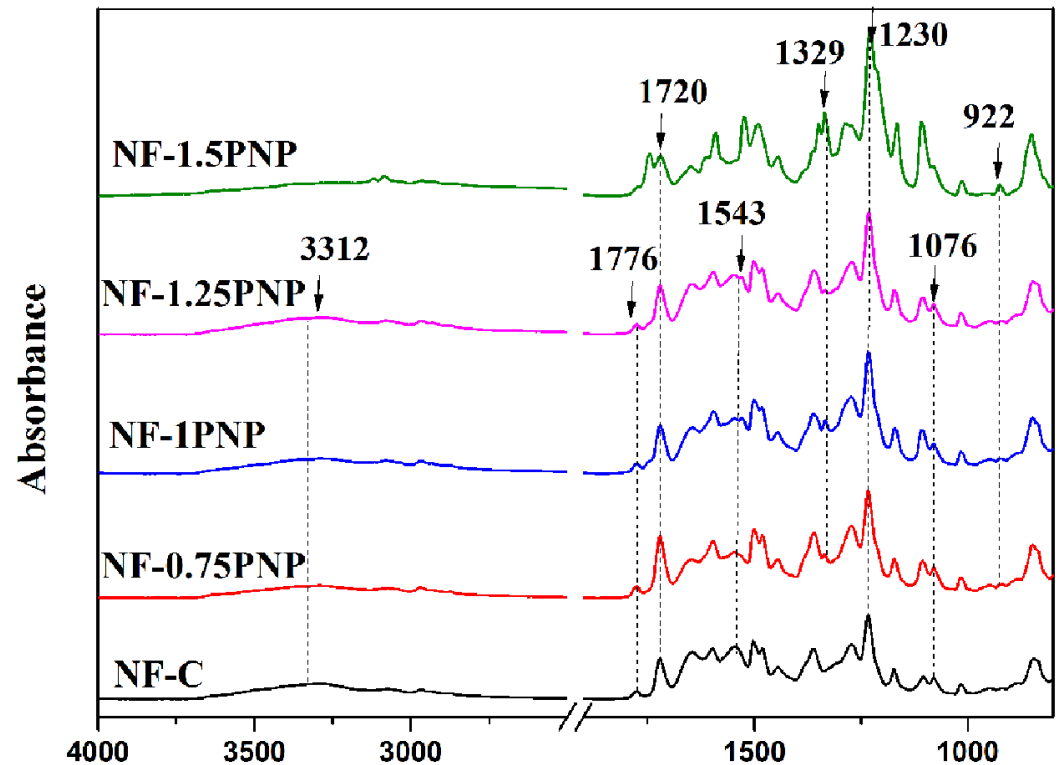

Figure 3. The ATR-FTIR spectra of the NF-C, NF-0.75PNP, NF-1PNP, NF-1.25PNP, and NF-1.5PNP membranes.

As shown in Figure 4, the deconvolution C1s, N1s, and O1s XPS spectra of NF$\mathrm{C}$ (a) and NF-1OL (b) membranes was performed. NF-C has carbon-related peaks at $284.55\left(-\mathrm{CH}_{2}-\mathrm{CH}_{2}-\right)$, $285.41\left(-\mathrm{CH}-\mathrm{NH}_{2}\right)$, and $287.91 \mathrm{eV}(-\mathrm{NH}-\mathrm{C}=\mathrm{O})$, nitrogen-related peaks at $399.43\left(-\mathrm{HC}-\mathrm{NH}_{2}\right), 400.07(-\mathrm{HN}-\mathrm{C}=\mathrm{O})$, and oxygen-related peaks at $530.84(\mathrm{Ph}-$ $\mathrm{O})$ and $531.56 \mathrm{eV}(-\mathrm{NH}-\mathrm{C}=\mathrm{O})$. While for NF-1PNP, which has carbon-related peaks at $284.28\left(-\mathrm{CH}_{2}-\mathrm{CH}_{2}-\right), 285.04(\mathrm{O}=\mathrm{C}-\mathrm{O})$, and $285.91 \mathrm{eV}\left(\mathrm{C}-\mathrm{NO}_{2}\right)$, nitrogen-related peaks at $399.20\left(-\mathrm{CH}-\mathrm{NH}_{2}\right), 399.80(-\mathrm{NH}-\mathrm{C}=\mathrm{O}), 400.76(-\mathrm{N}-\mathrm{H})$, and $405.70 \mathrm{eV}\left(\mathrm{C}-\mathrm{NO}_{2}\right)$ [34], oxygenrelated peaks at $530.82(\mathrm{Ph}-\mathrm{O}-), 531.56(-\mathrm{NH}-\mathrm{C}=\mathrm{O}), 532.21\left(-\mathrm{O}=\mathrm{C}-\mathrm{O}^{*}\right), 532.90\left(-\mathrm{NO}_{2}\right)$, and $533.70 \mathrm{eV}\left(-\mathrm{O}=\mathrm{C}-\mathrm{O}^{*}\right)[35]$. The new peak at $533.70 \mathrm{ev}\left(-\mathrm{O}=\mathrm{C}-\mathrm{O}^{*}\right)$ indicates that ester group formed on the surface, which is consistent with the result characterized by ATR-FTIR [30]. The amide group is formed by the reaction of the free terminal amino group of the top layer of the cross-linked PEI with TMC. The formation of amide bond is significant for the stability of the overall structure of composite nanofiltration membrane, which makes the top layer connected with the substrate and avoids the top layer falling off the substrate in organic solvents. Additionally, the peaks indicating the $\mathrm{O}=\mathrm{C}-\mathrm{O}^{*}$ species signify the presence of ester groups, which agrees with the structure displayed in Scheme 1. 

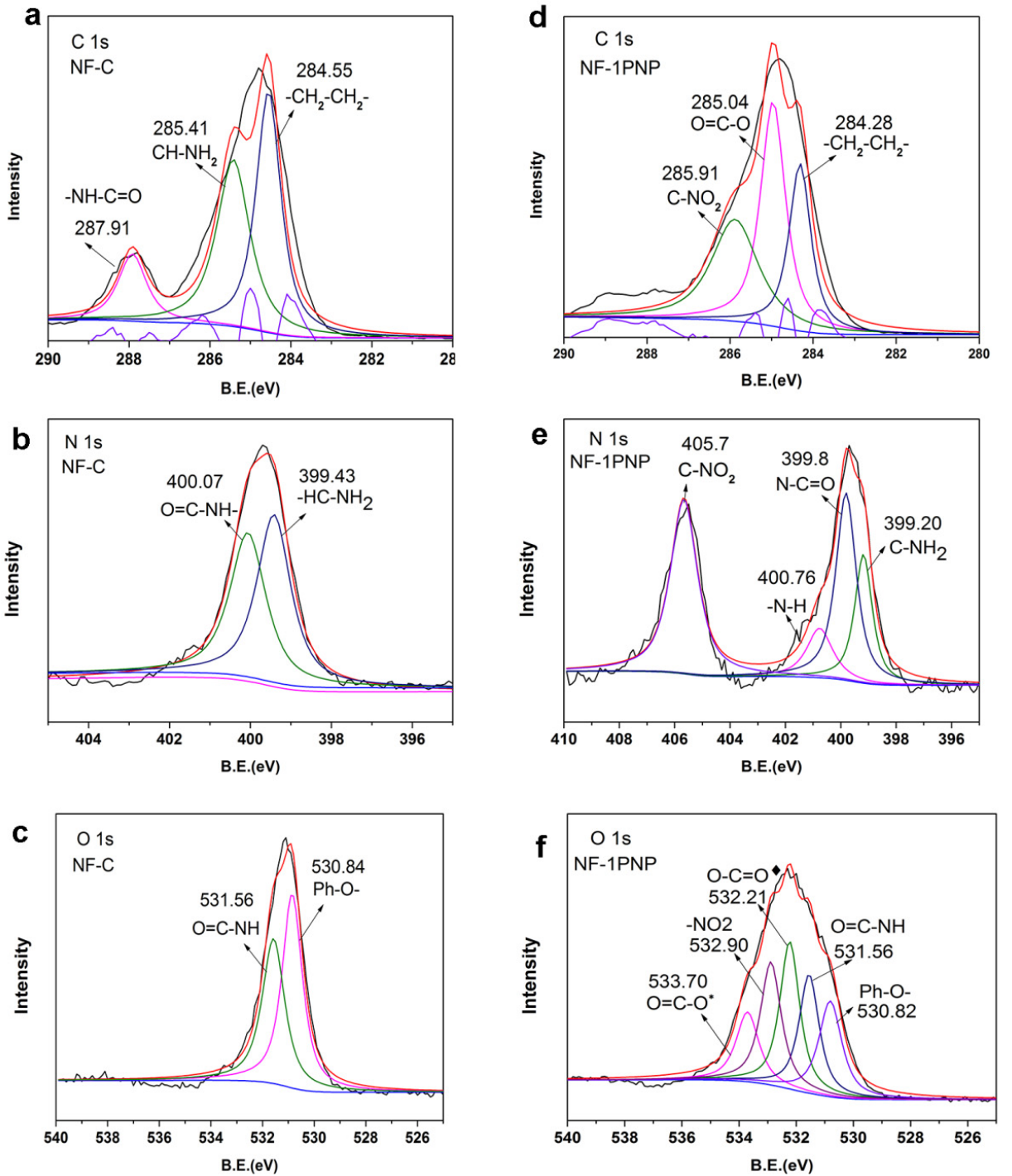

Figure 4. The deconvolution $\mathrm{C} 1 \mathrm{~s}, \mathrm{~N} 1 \mathrm{~s}$, and O1s XPS spectra of NF-C (a-c) and NF-1OL (d-f) membranes.<smiles>COc1cc([18O])cc(C(Cl)(Cl)Cl)c1</smiles>
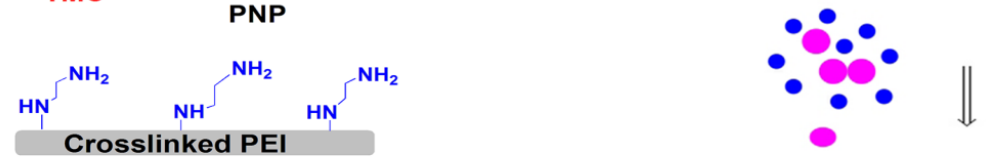

IP
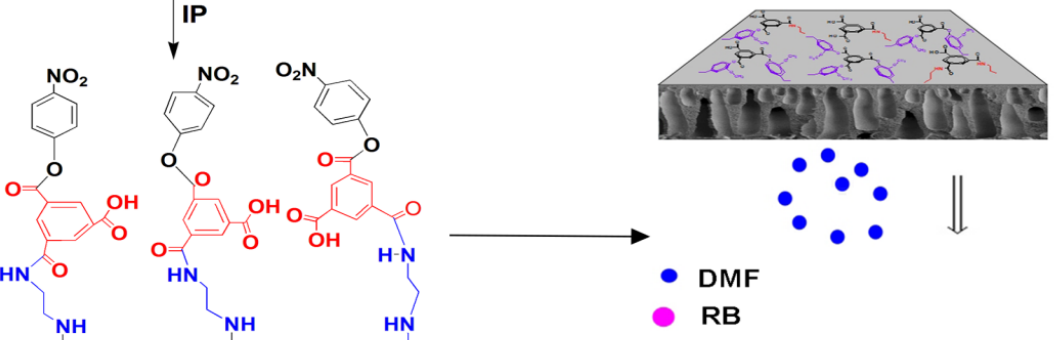

\section{Crosslinked PEI}

Scheme 1. A possible interfacial polymerization mechanism of P-nitrophenol reacting with TMC. 


\subsection{Membrane Performance}

Figure 5 displays the effect of PNP concentration on membrane separation performance in DMF. The performance of NF-C is relatively poor with a rejection of $63 \%$ and permeance of $0.1 \mathrm{~L} \mathrm{~m}^{-2} \mathrm{~h}^{-1} \mathrm{bar}^{-1}$. With the addition of PNP, the separation performance of membrane increased gradually. NF-0.5PNP had a rejection of $83 \%$ and a permeance of $0.8 \mathrm{~L} \mathrm{~m}^{-2} \mathrm{~h}^{-1} \mathrm{bar}^{-1}$. As PNP concentration increased, the permeance of NF-1PNP reached to $2.1 \mathrm{~L} \mathrm{~m}^{-2} \mathrm{~h}^{-1} \mathrm{bar}^{-1}$, at the same time, the rejection reached $99 \%$. Then, the permeance of NF-1.25PNP and NF-1.5PNP membrane decreased to 2.0 $\mathrm{L} \mathrm{m}^{-2} \mathrm{~h}^{-1} \mathrm{bar}^{-1}$ and $1.87 \mathrm{~L} \mathrm{~m}^{-2} \mathrm{~h}^{-1}$ bar $^{-1}$, respectively. For NF-PNP membrane, it can be noted that the membrane prepared with higher PNP concentration can produce higher rejection.

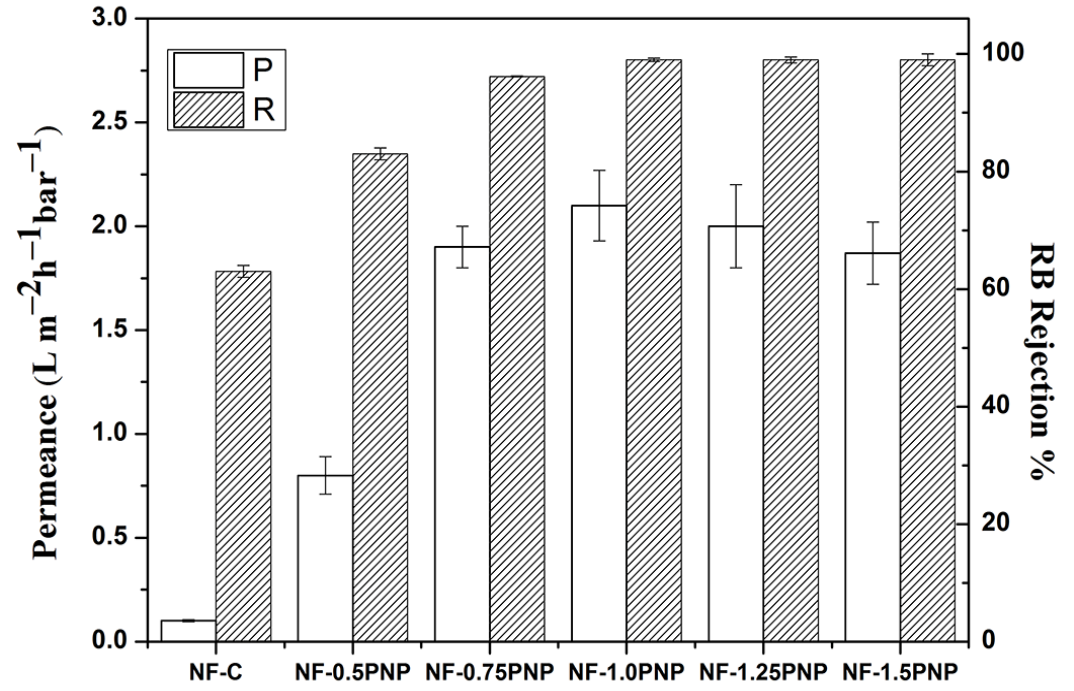

Figure 5. The effect of PNP concentration on the membrane performance in DMF.

Figure 6 displays the effect of TMC concentration on membrane performance. With the increase of TMC concentration, the rejection of the membrane gradually increased to $99 \%$ until it reached $0.1 \%$. When the TMC concentration continues to increase from 0.12 to 0.14 , the rejection rate of the membrane decreases slightly, which may be due to the hydrolysis of high concentration TMC, resulting in the production of carboxylic acid on the membrane surface, which affects the performance of the membrane.

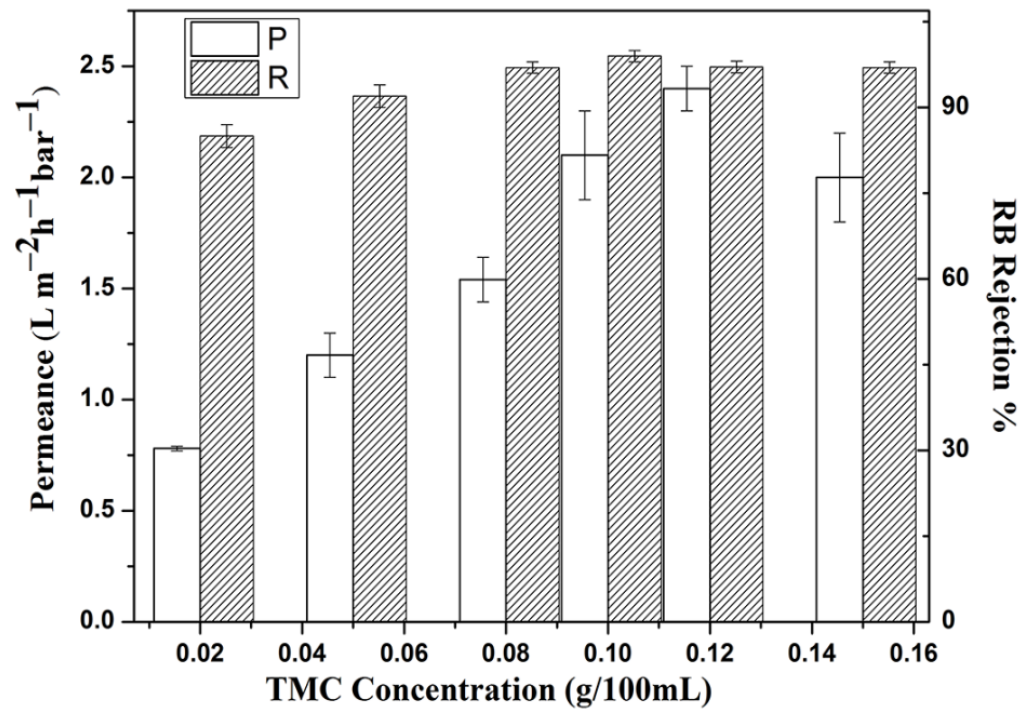

Figure 6. The effect of TMC concentration on the membrane performance in DMF. 
The consumption rate of PNP and TMC can be obtained from the analysis of the absorbance change of UV. When the acid chloride was added into the system, the absorption intensity of PNP decreases with the progress of interfacial polymerization. Interfacial polymerization refers to the process that polymerization occurs at the interface between two immiscible phases. In the process of interfacial polymerization, aqueous monomers usually diffuse to organic phase, which means that PNP diffuses to the organic phase of TMC. Therefore, as shown in the figure, it can be seen from Figure 7 that the change of TMC concentration is not obvious compared with PNP.

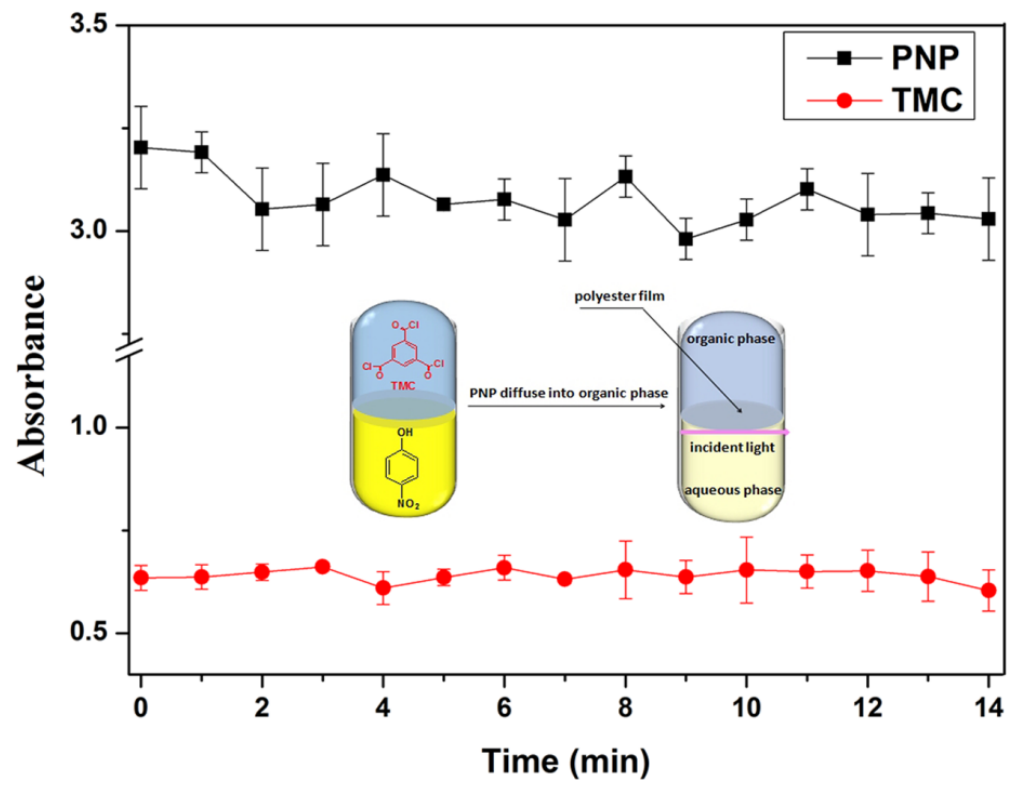

Figure 7. UV-vis absorbance of the aqueous solution over reaction time of IP between LWP and TMC.

The effect of reaction time on the interfacial polymerization and the separation performance of the membrane was also studied. As shown in Figure 8, with the increase of reaction time, the rejection of the membrane gradually increases until it reached 1 minute, then, the rejection does not change significantly, but the permeance gradually decreases, which may be due to the denser membrane structure caused by reaction time.

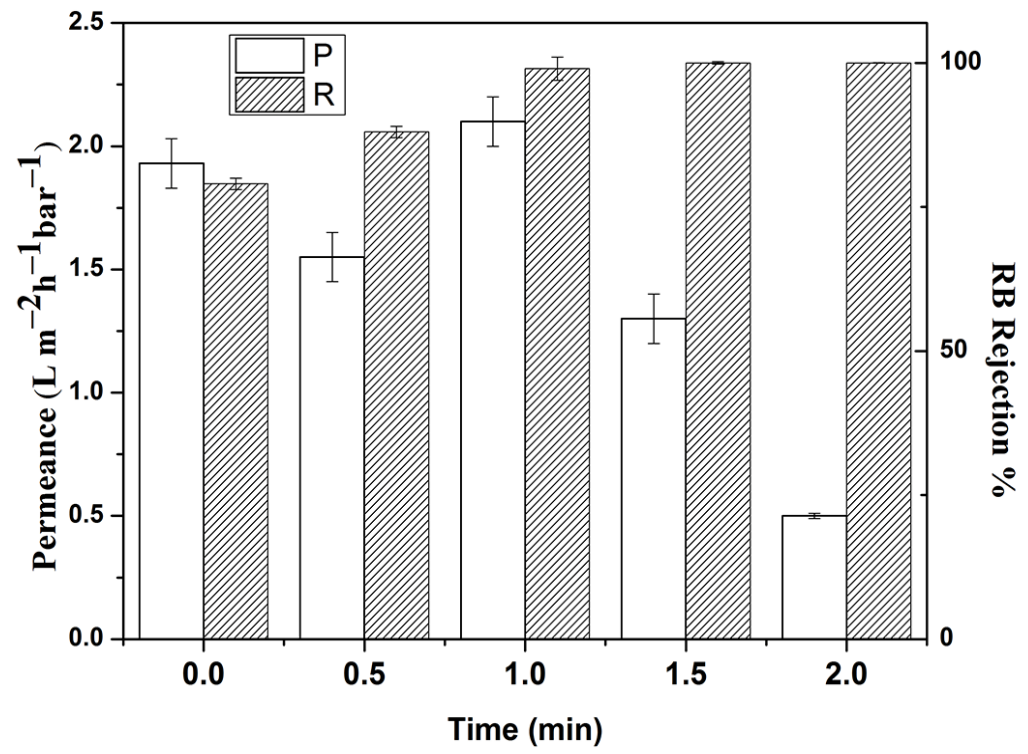

Figure 8. The influence of reaction time on NF-1PNP membrane performance. 
As shown in Figure 9, the contact angle of $65^{\circ}$ for NF-C, $73^{\circ}$ for NF-0.5PNP, $81^{\circ}$ for NF-0.75PNP, $83^{\circ}$ for NF-1PNP, $79^{\circ}$ for NF-1.25PNP, and $71^{\circ}$ for NF-1.5PNP. With the PNP concentration increasing from 0.5 to 1 , the contact angle of the prepared membrane increased to $83^{\circ}$. However, when the PNP concentration continues to increase, the contact angle decreases, which may be due to the introduction of more phenolic hydroxyl groups with the increase of PNP concentration, which reduces the hydrophobicity of the membrane.

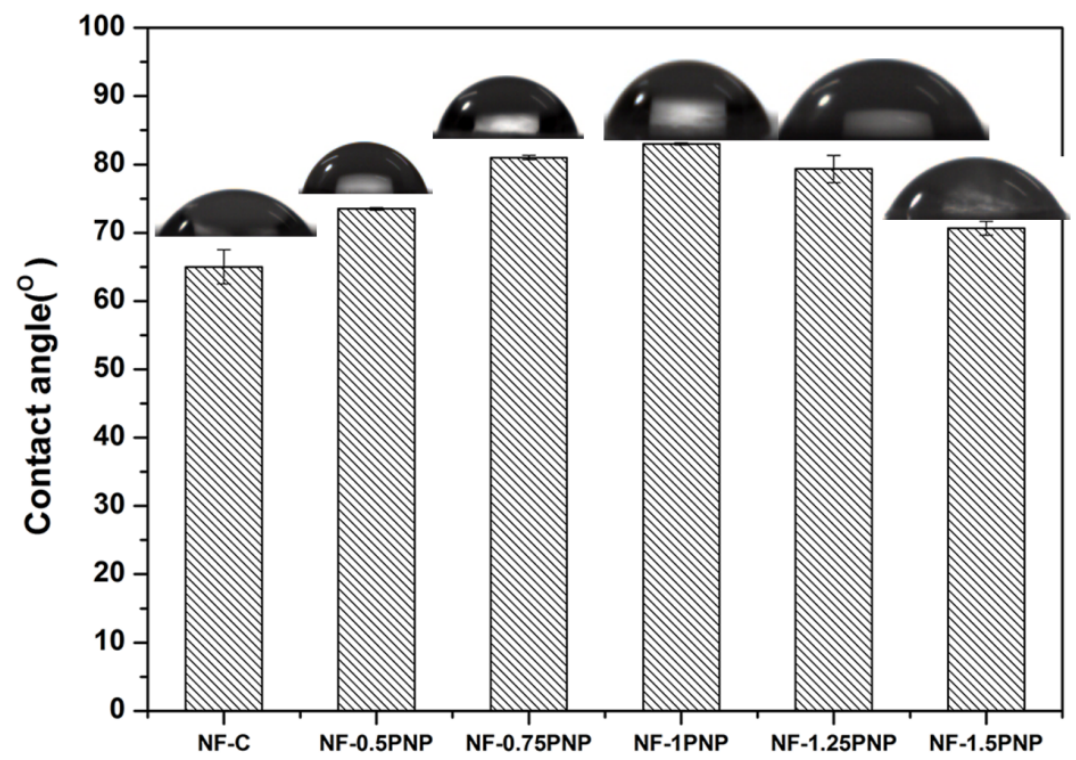

Figure 9. The static water contact angles of NF-C, NF-0.5PNP, NF-0.75PNP, NF-1PNP, NF-1.25PNP, and NF-1.5PNP membranes.

Figure 10 showed the average pore diameters of the two membranes including NF1PNP and NF-1.25PNP, which are 0.40 and $0.36 \mathrm{~nm}$ respectively. The pore sizes of both membranes are all within the range of nanofiltration membrane. The results indicate that the prepared membrane with higher concentration had higher reaction activity and smaller pore size thanthe selective layer.

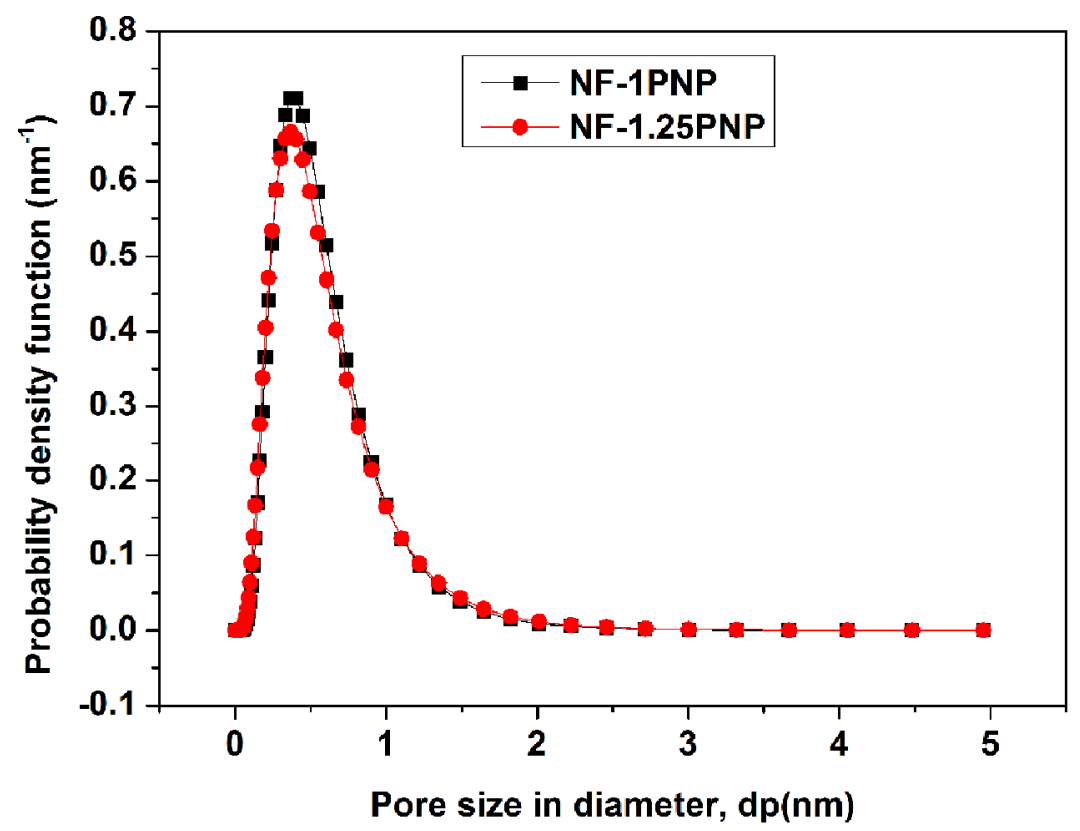

Figure 10. Pore size distribution of NF-1PNP and NF-1.25PNP membrane. 
The long-term stability of NF-1PNP in DMF solution was further studied. As shown in Figure 11, during the $36 \mathrm{~h}$ separation process, the permeability of the membrane was maintained at about $2.1 \mathrm{~L} \mathrm{~m}^{-2} \mathrm{~h}^{-1} \mathrm{bar}^{-1}$, and the rejection of RB was maintained at about $98 \%$, indicating that it has strong stability in DMF.

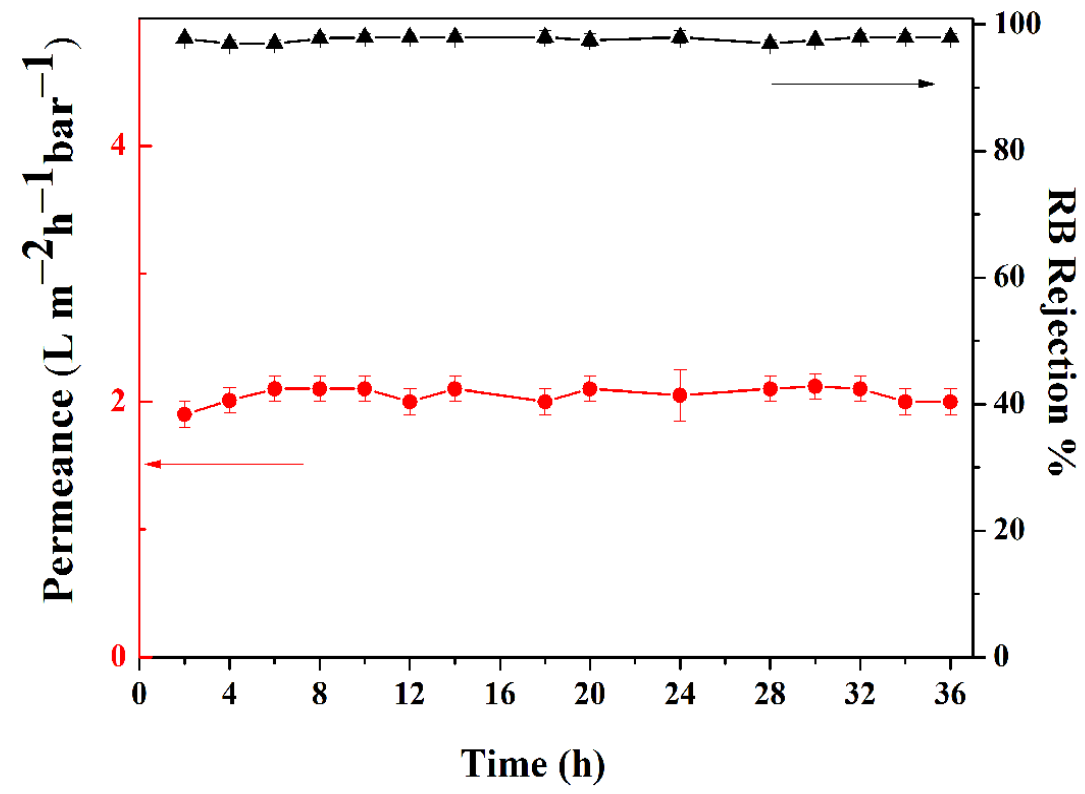

Figure 11. The long-term stability test of NF-1PNP when separating $0.01 \mathrm{~g} \cdot \mathrm{L}^{-1} \mathrm{RB}$ from DMF for $36 \mathrm{~h}$.

Table 1 lists the separation performance of some polymeric membranes in DMF. For instance, a crosslinked PVDF-membrane was synthesized, with the permeance about 2.16.0 $\mathrm{L} \mathrm{m}^{-2} \mathrm{~h}^{-1} \mathrm{bar}^{-1}$ and RB rejection of 75.0\% [10]. A PMDA-MDA polyimide membrane was prepared using a gelation/non-solvent-induced phase separation method, showing DMF permeance around $2.16 \mathrm{~L} \mathrm{~m}^{-2} \mathrm{~h}^{-1} \mathrm{bar}^{-1}$ with the RB rejection of $96 \%$ [36]. The synthesized NF-1PNP in this work shows the comparable separation performance in the organic solvent of DMF.

Table 1. A comparison of OSN performance for different membranes in DMF.

\begin{tabular}{|c|c|c|c|c|c|c|}
\hline Membrane & $\begin{array}{l}\text { Solven } \\
\text { (L m }{ }^{-}\end{array}$ & $\begin{array}{l}\text { meance } \\
\left.\text { bar }^{1}\right)\end{array}$ & Solute & $\begin{array}{l}\text { Mw of the } \\
\text { Solute } \\
\left(\mathrm{g} \mathrm{mol}^{-1}\right)\end{array}$ & $\begin{array}{c}\text { Rejection } \\
(\%)\end{array}$ & Ref. \\
\hline PVDF & DMF & 2.16 & Rose Bengal & 1017 & 75 & [10] \\
\hline Crolsslinked-P84 & DMF & 1.67 & Styreneoligomer & 200 & 93 & [37] \\
\hline PMDA-ODA & DMF & 2.50 & Rose Bengal & 1017 & 96 & [36] \\
\hline $\mathrm{PDA} / \beta-\mathrm{CD}$ on $\mathrm{P} 84$ & DMF & 6.30 & Rose Bengal & 1017 & 99 & [38] \\
\hline PMDA-MDA & DMF & 6.10 & Rose Bengal & 1017 & 92 & [39] \\
\hline DBX-crosslinkedPBI & DMF & 6.00 & PEG & 2000 & 95 & [40] \\
\hline $\begin{array}{l}\text { GO in PBI on PP } \\
\text { Support }\end{array}$ & DMF & 15.00 & $\begin{array}{l}\text { Mepenzolate- } \\
\text {-Bromide }\end{array}$ & 420 & 99 & [41] \\
\hline PEI-TMC-GQD & DMF & 1.83 & Rose Bengal & 1017 & 99 & [42] \\
\hline NF-1PNP & DMF & 2.20 & Rose Bengal & 1017 & 98 & $\begin{array}{l}\text { This } \\
\text { work }\end{array}$ \\
\hline
\end{tabular}

\section{Conclusions}

A kind of thin film composite polyamide NF membrane with stable organic resistance has been synthesized via the interfacialpolymerization between a new phenolic monomer of PNP and trimesoyl chloride on the surface of cross-linkedpolyetherimide. For NF-PNP membrane, it can be noted that the membrane prepared with higher PNP concentration can produce higher rejection. The optimal NF-1PNP membrane had a $98 \%$ rejection for dye RB and a permeance of $2.1 \mathrm{~L} \mathrm{~m}^{-2} \mathrm{~h}^{-1} \mathrm{bar}^{-1}$ in DMF. The average pore diameter 
of the two membranes including NF-1PNP and NF-1.25PNP, which is 0.40 and $0.36 \mathrm{~nm}$ respectively. The thickness of the top-layer on top of the macrovoids $618 \mathrm{~nm}$ for NF0.75PNP.The root mean square (RMS) values of surface roughness are $10.02 \pm 0.4 \mathrm{~nm}$, $11.2 \pm 0.6 \mathrm{~nm}$, and $42.15 \pm 0.5 \mathrm{~nm}$ for NF-0.75PNP, NF-1PNP, and NF-1.5PNP, respectively. For NF-PNP membrane, it can be noted that the membrane prepared with higher PNP concentration can produce higher rejection. Finally, NF-1NP showed a stable performance when separating $0.01 \mathrm{~g} \cdot \mathrm{L}^{-1} \mathrm{RB}$ for $36 \mathrm{~h}$ in DMF. The synthesized NF-1PNP membranes show the comparable separation performance in DMF, which provides a new way for the utilization of p-nitrophenol. The results suggest a promising and transferable method to enhance the separation performance of OSN membranes.

Author Contributions: A.Z.: conceptualization, resources, writing, supervision; L.L.: software; M.L.: formal analysis; Q.C.: methodology. All authors have read and agreed to the published version of the manuscript.

Funding: This research was funded by National College Students Innovation and Entrepreneurship Training Program. Grant Number: 202110377029. University Natural Science Research Major Project of Anhui Province, Grant Number: KJ2019ZD043.

Conflicts of Interest: The authors declare that they have no known competing financial interests or personal relationships that could have appeared to influence the work reported in this paper.

\section{References}

1. Shi, G.M.; Feng, Y.; Li, B.; Tham, H.M.; Lai, J.Y.; Chung, T.S. Recent progress of organic solvent nanofiltration membranes. Prog. Polym. Sci. 2021, 12, 101470. [CrossRef]

2. Scharzec, B.; Holtkötter, J.; Bianga, J.; Dreimann, J.M.; Vogt, D.; Skiborowski, M. Conceptual study of co-product separation from catalyst-rich recycle streams in thermomorphic multiphase systems by OSN. Chem. Eng. Res. Des. 2020, 157, 65-76. [CrossRef]

3. Liu, G.; Jin, W. Pervaporation membrane materials: Recent trends and perspectives. J. Membr. Sci. 2021, 636, 119557. [CrossRef]

4. Hadizade, G.; Binaeian, E.; Emami, M.R.S. Preparation and characterization of hexagonal mesoporous silica/polyacrylamide nanocomposite capsule (PAM-HMS) for dye removal from aqueous solutions. J. Mol. Liq. 2017, 238, 499-507. [CrossRef]

5. Werth, K.; Kaupenjohann, P.; Skiborowski, M. The potential of organic solvent nanofiltration processes for oleochemical industry. Sep. Purif. Technol. 2017, 182, 185-196. [CrossRef]

6. White, L.S.; Nitsch, A.R. Solvent recovery from lube oil filtrates with a polyimide membrane. J. Membr. Sci. 2000, 179, 267-274. [CrossRef]

7. Zhang, Y.; Song, Q.; Liang, X.; Wang, J.; Jiang, Y.; Liu, J. High-flux, high-selectivity loose nanofiltration membrane mixed with zwitterionic functionalized silica for dye/salt separation. Appl. Surf. Sci. 2020, 515, 146005. [CrossRef]

8. Feng, W.; Li, J.; Fang, C.; Zhang, L.; Zhu, L. Controllable thermal annealing of polyimide membranes for highly-precise organic solvent nanofiltration. J. Membr. Sci. 2022, 643, 120013. [CrossRef]

9. Loh, X.X.; Sairam, M.; Bismarck, A.; Steinke, J.H.G.; Livingston, A.G.; Li, K. Crosslinked integrally skinned asymmetric polyaniline membranes for use in organic solvents. J. Membr. Sci. 2009, 326, 635-642. [CrossRef]

10. Matthias, M.; Cédric, V.; Marloes, T.; Guy, K.; Vankelecom, I. Crosslinked PVDF-membranes for Solvent Resistant Nanofiltration. J. Membr. Sci. 2018, 566, 223-230.

11. Chisca, S.; Duong, P.H.H.; Emwas, A.H.; Sougrat, R.; Nunes, S.P. Crosslinked copolyazoles with a zwitterionic structure for organic solvent resistant membranes. Polym. Chem. 2015, 6, 543-554. [CrossRef]

12. Wang, X.; Wang, N.; Li, X.; An, Q.F. A review of nano-confined composite membranes fabricated inside the porous support. Adv. Membr. 2021, 1, 100005. [CrossRef]

13. Zhu, J.; Yuan, S.; Wang, J.; Zhang, Y.; Tian, M.B.; Bruggen, B. Microporous organic polymer-based membranes for ultrafast molecular separations. Prog. Polym. Sci. 2020, 110, 101308. [CrossRef]

14. Feng, Y.; Weber, M.; Maletzko, C.; Chung, T.S. Fabrication of organic solvent nanofiltration membranes via facile bioinspired one-step modification. Chem. Eng. Sci. 2019, 198, 74-84. [CrossRef]

15. Zhang, H.; Mao, H.; Wang, J.; Ding, R.; Du, Z.; Liu, J.; Cao, S. Mineralization-inspired preparation of composite membranes with Polyethyleneimine-Nanoparticle hybrid active layer for solvent resistant nanofiltration. J. Membr. Sci. 2014, 470, 70-79. [CrossRef]

16. Peyravi, M.; Jahanshahi, M.; Rahimpour, A.; Javadi, A.; Hajavi, S. Novel thin film nanocomposite membranes incorporated with functionalized $\mathrm{TiO}_{2}$ nanoparticles for organic solvent nanofiltration. Chem. Eng. J. 2014, 241, 155-166. [CrossRef]

17. Farahani, M.H.D.A.; Hua, D.; Chung, T.S. Cross-linked mixed matrix membranes (MMMs) consisting of amine-functionalized multi-walled carbon nanotubes and P84 polyimide for organic solvent nanofiltration (OSN) with enhanced flux. J. Membr. Sci. 2018, 548, 319-331. [CrossRef] 
18. Xu, S.J.; Luo, L.H.; Tong, Y.H.; Shen, Q.; Xu, Z.L.; Wu, Y.Z.; Yang, H. Organic solvent nanofiltration (OSN) membrane with polyamantadinamide active layer for reducing separation performance inconformity. Sep. Purif. Technol. 2022, $278,119582$. [CrossRef]

19. Duong, P.H.H.; Anjum, D.H.; Peinemann, K.V.; Nunes, S.P. Thin porphyrin composite membranes with enhanced organic solvent transport. J. Membr. Sci. 2018, 563, 684-693. [CrossRef]

20. Huang, S.H.; Hsu, C.J.; Liaw, D.J.; Hu, C.C.; Lee, K.R.; Lai, J.Y. Effect of chemical structures of amines on physicochemical properties of active layers and dehydration of isopropanol through interfacially polymerized thin-film composite membranes. $J$. Membr. Sci. 2008, 307, 73-81. [CrossRef]

21. Ghosh, A.K.; Jeong, B.H.; Huang, X.; Hoek, E.M.V. Impacts of reaction and curing conditions on polyamide composite reverse osmosis membrane properties. J. Membr. Sci. 2008, 311, 34-45. [CrossRef]

22. Hai, Y.; Zhang, J.; Shi, C.; Zhou, A.; Bian, C.; Li, W. Thin film composite nanofiltration membrane prepared by the interfacial polymerization of 1,2,4,5-benzene tetracarbonyl chloride on the mixed amines cross-linked poly(ether imide) support. J. Membr. Sci. 2016, 520, 19-28. [CrossRef]

23. Zhou, A.; Shi, C.; He, X.; Fu, Y.; Anjum, A.W.; Zhang, J.; Li, W. Polyarylester nanofiltration membrane prepared from monomers of vanillic alcohol and trimesoyl chloride. Sep. Purif. Technol. 2018, 193, 58-68. [CrossRef]

24. Zhai, Z.; Jiang, C.; Zhao, N.; Dong, W.; Li, P.; Sun, H.; Niu, Q.J. Polyarylate membrane constructed from porous organic cage for high-performance organic solvent nanofiltration. J. Membr. Sci. 2020, 595, 117505. [CrossRef]

25. Zhou, A.; Almijbilee, M.M.A.; Zheng, J.; Wang, L. A thin film composite membrane prepared from monomers of vanillin and trimesoyl chloride for organic solvent nanofiltration. Sep. Purif. Technol. 2021, 263, 118394. [CrossRef]

26. Wang, Y.; Gu, J.; Zhou, A.; Kong, A.; Almijbilee, M.M.A.; Zheng, X.; Zhang, J.; Li, W. Poly[acrylate-co-amide] network composite via photopolymerization for organic solvent nanofiltration separation. Sep.Purif. Technol. 2020, 246, 116855. [CrossRef]

27. Park, S.H.; Yang, C.; Ayaril, N.; Szekely, G. Solvent-Resistant Thin-Film Composite Membranes from Biomass-Derived Building Blocks: Chitosan and 2,5-Furandicarboxaldehyde. ACS Sustain. Chem. Eng. 2021, 10, 998-1007. [CrossRef]

28. Weng, R.; Huang, X.; Liao, D.; Xu, S.; Peng, L.; Liu, X. A novel cellulose/chitosan composite nanofiltration membrane prepared with piperazine and trimesoyl chloride by interfacial polymerization. RSC Adv. 2020, 10, 1309-1318. [CrossRef]

29. Park, S.H.; Alammar, A.; Fulop, Z.; Pulido, B.A.; Nunes, S.P.; Szekely, G. Hydrophobic thin film composite nanofiltration membranes derived solely from sustainable sources. Green Chem. 2021, 23, 1175-1184. [CrossRef]

30. Li, W.; Bian, C.; Fu, C.; Zhou, A.; Shi, C.; Zhang, J. A poly(amide-co-ester) nanofiltration membrane using monomers of glucose and trimesoyl chloride. J. Membr. Sci. 2016, 504, 185-195. [CrossRef]

31. Soyekwo, F.; Zhang, Q.; Gao, R.; Qu, Y.; Lin, C.; Huang, X.; Zhu, A.; Liu, Q. Cellulose nanofiber intermediary to fabricate highly-permeable ultrathin nanofiltration membranes for fast water purification. J. Membr. Sci. 2017, 524, 174-185. [CrossRef]

32. Tarboush, B.J.A.; Rana, D.; Matsuura, T.; Arafat, H.A.; Narbaitz, R.M. Preparation of thin-film-composite polyamide membranes for desalination using novel hydrophilic surface modifying macromolecules. J. Membr. Sci. 2009, 325, 166-175. [CrossRef]

33. Sanadhya, S.G.; Oswal, S.; Parmar, K.C. Synthesis and characterization of aliphatic-aromatic polyesters using interfacial polycondensation technique. J. Chem. Pharm. Res. 2014, 6, 705-714.

34. Albrecht, W.; Seifert, B.; Weigel, T.; Schossig, M.; Holländer, A.; Groth, T.; Hilke, R. Amination of Poly(ether imide) Membranes Using Di- and Multivalent Amines. Macromol. Chem. Phys. 2003, 204, 510-521. [CrossRef]

35. Roy, S.; Yue, C.Y.; Venkatraman, S.S.; Ma, L.L. Low-temperature (below Tg) thermal bonding of COC microfluidic devices using UV photografted HEMA-modified substrates: High strength, stable hydrophilic, biocompatible surfaces. J. Mater. Chem. 2011, 21, 15031-15040. [CrossRef]

36. Li, Y.; Cao, B.; Li, P. Effects of dope compositions on morphologies and separation performances of PMDA-ODA polyimide hollow fiber membranes in aqueous and organic solvent systems. Appl. Surf. Sci. 2019, 473, 1038-1048. [CrossRef]

37. Toh, Y.H.S.; Lim, F.W.; Livingston, A.G. Polymeric membranes for nanofiltration in polar aprotic solvents. J. Membr. Sci. 2007, 301, $3-10$.

38. Zhang, Y.; Sun, H.; Sadam, H.; Liu, Y.; Shao, L. Supramolecular chemistry assisted construction of ultra-stable solvent-resistant membranes for angstrom-sized molecular separation. Chem. Eng. J. 2019, 371, 535-543. [CrossRef]

39. Li, Y.; Xue, J.; Zhang, X.; Cao, B.; Li, P. Formation of Macrovoid-Free PMDA-MDA Polyimide Membranes Using a Gelation/NonSolvent-Induced Phase Separation Method for Organic Solvent Nanofiltration. Ind. Eng. Chem. Res. 2019, 58, 6712-6720. [CrossRef]

40. Valtcheva, I.B.; Kumbharkar, S.C.; Kim, J.F.; Bhole, Y.; Livingston, A.G. Beyond polyimide: Crosslinked polybenzimidazole membranes for organic solvent nanofiltration(OSN) in harsh environments. J. Membr. Sci. 2014, 457, 627. [CrossRef]

41. Fei, F.; Cseri, L.; Szekely, G.; Blanford, C.F. Robust covalently cross-linked polybenzimidazole/graphene oxide membranes for high-flux organic solvent nanofiltration. ACS Appl. Mater. Interfaces 2018, 10, 16140-16147. [CrossRef]

42. Liang, Y.; Li, C.; Li, S.; Su, B.; Hu, M.Z.; Gao, X. Graphene quantum dots(GQDs)-polyethyleneimine as interlayer for the fabrication of high performanceorganic solvent nanofiltration (OSN) membranes. Chem. Eng. J. 2020, 380, 122462. [CrossRef] 